\title{
Analysis of Chinese English from the functional equivalence theory
}

\author{
He Weiwei ${ }^{1, a}$ \\ ${ }^{1}$ Jiangxi college of foreign studies,NanChang,330099, China \\ a HeWeiwei@yeah.net
}

Keywords: Poster design; Special materials; Application research; Innovative design; Material selection.

\begin{abstract}
Poster design is a kind of comprehensive thinking behavior. This article from the ancient and modern, the evolution of the design of the poster design of the detailed discussion, at the same time using a wealth of examples, reflecting the selection of materials to grasp the overall style of the poster design plays an important role. In order to make the designers more aware of the correct choice of the material of the poster, it can enhance the level of the seemingly single text carrier to art, and endow it with rich connotation. In order to allow readers to appreciate the text at the same time to appreciate the beauty of the material, so that the text in the beauty of the material set off the order of its sublimation. Poster is the ladder of human progress, is an important tool for the heritage of human civilization. In the life of modern people, posters are indispensable. In this era of the pursuit of beauty, the importance of the design of the poster is also naturally highlighted. Posters as the carrier of information, along with the long history of human development process, in the dissemination of knowledge to the readers at the same time, to give them the enjoyment of the United states. Therefore, good posters not only provide static reading, but also should be a static drama that can be used for the flow of appreciation, taste and collection. The poster design, each designer will have its own focus and use some ideas, pay attention to color, with abstract graphics and character color to express the contents of the book, some focus on the complete form of a book to tell the story. From the full significance of poster binding is not binding and there can be no poster posters, this is even the spirit cannot do without the same body, even if the narrow limits of art in the poster design range, no poster binding, will also tend to be humble and lack of beauty, white appearance is not difficult to imagine. However, the information is delicious, need a good environment and good dishes containing will give people to enjoy, using material posters in the layout of a good environment for information expression is as important as the poster.
\end{abstract}

\section{Introduction}

Poster is the carrier of human's thought, and it is the eternal life of the inner culture. Whenever people holding posters by page read, soft or hard, beautiful or elegant appearance and unique personality of the binding material, feeling and imagination inadvertently bring readers a variety of posters outside the content. This is the material of the poster to bring us the beauty of reading, a character of the mold, a kind of life sentiment, a new look at the world and cognition. The poster is covered by the cover, only to open it to understand its theme. It is different from the picture, can be intuitively understood and accepted by many people. Reading is a matter of personal, it takes a lot of time, eyes and hands always keep on moving. So we say, a book is the product of the combination of the two aspects: that reflects the personality of the design style and reflect the personality of the poster content[1]. Poster design is a kind of comprehensive thinking, it is not only considered the poster cover, lining, title page, preface, catalogue, text, fonts, images, text, lines, ornaments and blank pages, copyright and other aspects, and the important factors for the choice of materials is also in poster design. Material, simple understanding refers to the texture and texture of the material, is a visual perception of the appearance of the phenomenon. It is the material itself to the height of the art and gives it a rich connotation, so that readers appreciate text at the same time to appreciate the beauty of the material, so that the text in the beauty of the material set off to order its sublimation. Since ancient times, the text is the basic element of information form, so far it is still dominant in the 
form of posters, but it is not the only element. Although the text, images, graphics, and signs in the poster...... Including all can mobilize the visual image capture and operations can convey the core of the content of the article, the image of the rational thinking of the expansion of tension, to fill even beyond the text of the expression of the value itself. But the material selection of the poster also makes the information knowledge have some incredible energy value and flow induced expression. The ancient and medieval European Chinese poster Bible is the organic combination of the handwriting of the two. Material is an important form of poster design. Select different materials will produce different design results, and then convey a different connotation of the poster. The paper with its own unique natural trace, through the latitude and longitude of the fiber, the color of the natural delicate, to show the incomparable charm of the paper. The beauty of the paper not only adds to the pleasure of our "book" life, but also the slow pace of life in the fast pace of life. What is the essence of the beauty of the paper? Is a kind of beauty is close, and we stay together morning and night surrounding life sense of intimacy, and bound by the paper posters both pure art appreciation of the beauty, more reading in the process of using to enjoy the visual, touch, hearing, smell, taste and sense of beauty blend five. Texture effect is also the material in the poster design application. Different textures have different physical characteristics, which will make people feel a variety of feelings. Texture can be divided into the texture of natural form and the texture of artificial form. Natural texture, texture, texture, natural texture, gives people close to the nature of beauty. The texture of an artificial form is produced by machining, such as plastics, synthetic metals, artificial leather, or the like. Give a person with precise, rational, stable psychological feeling. Appropriate use of texture effect, in the poster design will give readers a new feeling, play a special effect. All kinds of specialty paper implied in line with countless changes of texture, length, thickness, bending, vertical and parallel combination; fluctuation of various forms are arranged, will produce out and static, strong and weak, fast and slow, internal and external..... The comparison of changes and ups and downs, rhythm, luxury and simplicity, elegance and vulgar[2], realistic and abstract meaning of the vivid expression and so on. Accurately grasp the content of binding material scale, using the expression of the myriads of changes to design posters, "director" a department of the "drama" to be not of the common sort by.

\section{The personalized application of materials in poster design}

An overview of the personalized application of materials in poster design. The history of human development, it can be described as a history of material development. Turn art history, we can clearly see the art through a specific material reflects the level of civilization and the development of the times. The stone age, the age of pottery, bronze age, the era of big industry and today's colorful information age, every time the emergence of new materials will bring a qualitative leap in the development of human. The material for art, it is not only the tangible material visual touch, is audible to the olfactory intangible material, even our thoughts and ideas can be defined as the expression of the art of media material. Its concept will continue to expand and extend along with the development of human civilization. The first is based on the works of artists to select the material to express the spirit of the connotation, all for how to articulate the spiritual connotation, to choose to set. Secondly, the selection of this material is largely determined by the sensitivity of the artist and the designer to the material, the level of the use of the material, and whether the material has a unique view of the individual. Material extended not only allows us to feel intuitively and simple to use, but requires a deep understanding and grasp of the original material properties, new material function and value, the material can not only in the visual and functional level to write upside of art and design, provide the possibility for modern art and design the development of the concept. In many modern works of art, artists are reasonable and bold choice of different materials and the unique texture of the material processing and appropriate combination, inspire people to the material of the bold use and the courage to discover. When we as a poster design touched by the beauty, often asked where the ripples in the form of posters on the beauty come from? That stored in the binding patterns within the mystery of conquest, unlimited fun and temptation emanating from the source, where? Calm analysis 
is not difficult to find, although elements of poster art the United States is in many aspects, but the poster design material as an important factor in design, will play a key role in an indispensable. A book gives people the feeling is not only from the poster's own spiritual values and exquisite design, the same, reasonable selection of sophisticated technology materials, use, combination, also can produce strong performance. Material with texture, texture, color of different can show a strong personality, to induce the reader to produce different psychological reflection. Attention should be paid to the visual component of the material[3], and the cold and warm feeling between the fingers. Different materials have different texture effects, light, no light, rough, delicate; there are cold, warm; soft, hard. Materials in the visual, feel must be with the content of the poster in their own ideological unity.

The role of paper materials in poster design. In the modern poster design, the main material of the paper is the most common. It is because it is more convenient, the cost of the material itself is relatively cheap, and the bulk of the printing and dissemination of the most practical and extensive. In the paper for the expression of the beauty of the decoration materials, is also a kind of exquisite beauty. We are from the "Silk Pattern", "', "ruled the wax pattern". "Rock grain" special paper such as convex concave surface and orderly texture, from the "Star", "transparent gauze shade", "Rainbow" and other special paper translucent hazy and wonderful, from the "gold foil", "gold and silver" is special paper such as luster, from "elegant" and other series of hands like the wrinkles on the wild disorder, can see the human in the papermaking process on equal to anything. Today's special paper exquisite beauty, fully embodies the "sky, earth, material and technology skillfully, the connotation of the four, can then be expressed by good" this sentence Chinese ancient sayings. The exquisite beauty of the decoration materials, fully embodies the infinite wisdom of human beings, reflects the people's wisdom and the day, common achievements in condensed material, its beauty, we appreciate the crystallization of natural and human a heaven-made match. Under the condition of cost permission, the paper, especially the special paper, has a strong expressive force. Features, texture, color, color, printing effect, the impact on the design of the paper is amazing. In the design of the poster materials, paper and printing process should be considered as the elements of the paper, the characteristics of the paper itself contribute to a more adequate performance of the design intent. The use of different paper or a combination of different materials, using different means of configuration, design, better and more perfect realization of visual and tactile, bring a unique vision and strong tactile effect to the reader, so that the transfer amount of proliferation of knowledge and art information poster[4].

The influence of materials on the poster. The exquisite beauty of the poster design, not only reflected in the printing and binding process, but also reflected in the material of the exquisite beauty of decoration. Today, more and more designers have recognized the exquisite beauty of the charm of the material itself, the material of exquisite beauty, into the overall aesthetic design posters, become a part of the United States indispensable binding. In the past, designers often complain about our books than in developed countries, beautiful, binding material is one of the important reasons behind it. Today, the rapid development of China's economy will greatly promote the development of art posters, this promotion is reflected in two aspects: first, the level of quality and binding material and developed countries more closely, some of our outstanding book binding material of the fine, even won the western publishing house praise; secondly, binding material modernization the graphic design posters, promote the concept of sublimation, binding material in our country is more and more exquisite posters of the grade, pay attention to quality, pay attention to the cultural connotation of material. The material has become an important part of the expression of creative graphic design posters can not be ignored. The rapid development of China's economy and material continuously enriched, fundamentally changing the poster art of our country face. The role of material beauty in poster design can't be exaggerated. To create a real work of art, is the need to train and cultivate the accumulation of. But designers must recognize the material beauty, it can exist independently, and in general become constitute the basic form of works of art beauty, the beauty of material binding, although also belongs to the primary aesthetic, but also constitute the basis for the graphic design poster beauty factor. 


\section{The role of special materials in poster design}

Development history of special materials. Modern poster design is a significant feature of the material, for the poster design material not only paper, but also plastic, metal, wood, fabric, leather, etc.. The texture, color and texture of all kinds of materials can show different personality and characteristics. Poster design is a kind of three-dimensional thinking action. The cover in the form of painting and stereotyped text format is the basis of binding only one package. Poster design should include: Poster form planning, information content weaving, visual graphics and text structure, the paper process settings...... From the "skin" to "flesh and blood" of the three dimension of the organization, in the past, the concept of the relationship between the external and internal. The use of materials in the poster is often the basic form that decides the information expression of the whole poster. The material of making the poster provides the first environment for the users. As a delicacy in different geographical environment to always give people different feelings, different poster material, it is given the effect will be not of the common sort of poster.

Helps to convey the message of the poster itself. Although the design of the poster is subject to the content of the theme, but not a narrow text interpretation or simple external packaging. The designer should excavate the deep meaning in the book. Search the main melody, rhythm arrangement of ups and downs, reflect the feeling of space in the art of time; all kinds of elements with rational consciousness to catch the meaning of the expression; use the material in place poster form and rigorous arrangement of text, correct pictures, more than white, time feeling reasonable color, personalized configuration...... Build a new form of new concepts, modern poster design art. Modern posters are made of paper, which is cheap and convenient, and its advantages are obvious, but the disadvantages are fatal. It can only be from the layout of the content to the poster content to express delivery, can not be called the reader from the external form of the poster to feel. And special materials can be easily done. For example, the poster content itself is Buddhist scriptures, so the use of glass and wood materials to better reflects the Buddhist pure natural conception. Different materials can produce different visual and tactile feel: fur soft, warm, feminine and strong; metal hard, cold, strong sense of the times; the cloth is simple, warm, nostalgic wood; neutral, simple, calm; glass clear, light and mysterious. The use of material to understand, often for the design of the icing on the cake.

Material can meet the function of the poster. Many excellent decoration works, the readers are "grab" is "engaging", they can form aesthetic readers into a deeper reverie. A good way to do this, to the pursuit of cultural connotation and the artistic style. The graphic design poster is a kind of "proposition", it belongs to the form of material from the contents of the book, and can not directly reproduce the contents; simulation it is not the real life, the specific graphic is not the contents of the book. Think in a limited picture, with readers to understand the entire contents of the manuscript, it is not realistic. The difficulty of graphic design aesthetic creation is here, it is very passive, must be subject to certain constraints. It also determines the special form of graphic design with the clearest material to create the maximum visual space, to express the profound connotation with the most concise language. So, to use good materials in the poster design. Only the material and the book itself, the meaning and value of the combination, complement each other. In order to create a good, consistent with the poster graphic design aesthetic readers[5].

\section{Summary}

In this paper, the material selection of the modern poster design occupies a very important position in the design. We are in a rapidly changing era of multimedia, various new media continue to impact our lives, but the poster is still indispensable media in our lives, whether ancient or modern people, both in the development process of poster material in the inheritance and innovation, this is the best proof of the vitality of the development of poster design. Therefore, in order to keep up with the pace of the times, material application and research will be a continuation and development of poster design creative design. Reasonable choice of materials using the poster design, can give full play to 
the "no written language, without the image of the painting" unbelievable performance and creativity. To make a poster of knowledge and artistic transmission, display a value-added role is not of the common sort. This is also an important means to create the Chinese Contemporary Poster Design form is worth a bold attempt.

\section{References}

[1] Yan Xiaoshan. Analysis of how to apply [J]. to modern decorative figure photography in Graphic Advertisement (Theory). 2016 (08).

[2] Huang Huang. On the use of color in print advertising [J]. big stage. 2015 (06).

[3] Zhao Zhao. An analysis of the application of figure photography in print advertising [J]. art and technology. 2015 (08).

[4] bow Lina, ye Qi. Creative photography in print advertising in the application of innovative research [J]. China National Expo. 2015 (12).

[5] Fang Bing. Thinking about the creative thinking of tourism print advertising [J]. art world. 2015 (01). 